\title{
Evaluating the Effectiveness of Self-regulation Strategy Training on Procrastination, Happiness and Academic Achievement
}

\author{
Kheironessa Naderi ${ }^{1}$, Hamid Taher NeshatDoost ${ }^{2,{ }^{*}}$ and Hooshang Talebi ${ }^{3}$ \\ ${ }^{1}$ Department of Psychology, Isfahan (Khorasgan) Branch, Islamic Azad University, Isfahan, Iran \\ ${ }^{2}$ Department of Psychology, Faculty of Education and Psychology, University of Isfahan, Isfahan, Iran \\ ${ }^{3}$ Department of Statistics, University of Isfahan, Isfahan, Iran \\ "Corresponding author: Department of Psychology, Faculty of Education and Psychology, University of Isfahan, Isfahan, Iran. Email: h.neshat@edu.ui.ac.ir
}

Received 2020 January 13; Accepted 2020 November 17.

\begin{abstract}
Objectives: This study was carried with the purpose of evaluating the effectiveness of self-regulation strategy training on procrastination, academic achievement, and happiness of 1st grade high school male and female students.

Methods: It is a quasi-experimental research with a pretest-posttest design involving a control group. Sixty students were selected by means of multistage cluster sampling plan and randomly grouped in 4 groups of 15 . Research instrument consisted of Solomon and Rothblum Academic Delay, Oxford Happiness, and Standard Academic Achievement Questionnaire. Test group received 8 selfregulation training sessions of 45-minute duration each.

Results: Results revealed that self-regulation training has a meaningful effect on dependent variables $(\mathrm{P}<0.001)$. In the presented model, "gender", "time and group", "interactive effect of gender and group", and "interactive effect of group and time" were meaningful, as opposed to the "interactive effect of gender and time" and "interactive effect of gender, group, and time" which lacked any significance.

Conclusions: Results of LSD post hoc test showed no meaningful difference between the mean happiness, procrastination, and academic achievement scores of experimental and control groups in the pretest stage. However, in the posttest and follow-up stage, the mean scores of the two groups differed significantly.
\end{abstract}

Keywords: Self-regulation Strategies, Procrastination, Happiness, Academic Achievement

\section{Background}

Hence, researchers have become evermore concerned about ways of inspiring students to be self-sufficient in terms of teaching and learning and manage their learning by themselves. In otherwords, personally bearing the responsibility of learning and exert control over their responses.

Academic procrastination, as one of the several factors acting against academic achievement, manifests in the form of weak functioning and, ultimately, leads to academic failure. Procrastination involves the deliberate delay in getting assignments done. Rothblum, Solomon \& Murakami (1) define procrastination as the act of delaying academic tasks to the point of experiencing subjective discomfort (2). Procrastination in academic performance creates problems such as reduced academic success or achievement, intensification of psychological complications, and loss of self-esteem and happiness in students (3). There are multiple causes for procrastination among students, the most important being stress, casualness, poor time-management, inability to control pleasing behaviors and lack of self-regulation, fear of failure, and the reluctance to do assignments. Pintrich (4) characterizes self-regulation as an active and organized process by virtue of which learners adjust their learning goals and work hard to self-monitor their cognition, motive, and behavior. Hence, self-regulated individuals initially reconsider their behavior and subsequently judge them as they proceed (4).

In recent years, procrastination has been expressed as a pattern of self-regulation failure in terms of not being able to control one's thoughts, excitements, emotions, and functioning in accordance to specific criteria. Park \& Rayne(5) percieved procrastination to be positively related to weak self-regulation skills and defensive behavior, such as self-handicapping strategies. Alternative findings Troia, (6) suggest procrastination to be reversely associated to academic score, academic self-regulation, and self-esteem, 
and, negatively related to self-regulation (7). Meantime, Hen \& Goroshit (8) conclude procrastination to be related to lower levels of self-regulated learning and academic selfefficacy.

Shortage of self-regulated behaviors, such as goalsetting, incorporation of strategies, and monitoring thought and learning process results in semi or nonaccomplishment of tasks (9). Research demonstrates that happy individuals enjoy a stronger sense of self-control and, in fulfilling their tasks, are more mindful of their advantages than their disadvantages (10). Investigation on procrastrating individuals indicates that those exhibiting more procrastination in doing their assignments, make less use of cognitive strategies (11).

Self-regulation is a skill by means of which individuals can outdo procrastination and alter their academic results, as well as their physical and mental well-being. Studies (12) suggest that learners who exercise self-regulation strategies show less acts of procrastination, and that, the adoption of learning strategies reduces procrastination in students. By helping students examine their multiple failures, self-regulation strategies, ultimately, improves students' active learning (13). At the same time, research has discovered that self-regulated learners have a stronger desire to seek academic counselling, information, and positive learning environment (14).

In the course of academic career, students experience different forms and levels of excitement. These emotions are related to their self-regulation strategies, learning motivation, self-regulation of learning, and academic achievement. In Pekrun's (15) opinion, academic emotions describe those group of emotions that are directly linked to academic activities or results. He describes the role of emotions in student self-regulation. The effect of emotions on learning and academic achievement is created by cognitive mediator and motivational variables, including motivation towards learning strategies and self-regulation of learning. Research Lyubomirsky, (16) indicates that happiness increases the cognitive and behavioral repertoire and the individual's attention, as opposed to sadness and depression that restricts the cognitive and behavioral repertoire and reduces attention. Numerous studies have addressed the role of happiness in learning, stating that youths with higher level of happiness exhibit a more active academic functioning and score a higher academic achievement (17). On the other hand, Karmen, Kinga \& Edit (18) argue that procrastination is mainly related to a negative view towards academic career, since, assignments are done with content solely when students exhibit a positive academic apprehension and a lower level of procrastination. Meanwhile, students exposed to a more desirable setting at school scored higher in their exams (19).
According to fear of failure theory, stress and anxiety are one of the reasons behind procrastination. Students come to believe that their assignments are stressful and procrastinate to avoid stress. At the same time, self- handicapping theory holds that self- handicapping process begins as soon as individuals are faced with an obstacle in the way of their fine functioning. The motive behind selfhandicapping is, generally, avoiding to hurt self-esteem (20). As held by temporal motivation theory, the individual fulfills the goals and assignments which are of greater value and reward to him quicker than those of lesser value and reward (21).

Multiple studies Pietrzak (22), Claessens et al. (23), Schoo (24) and Bondarenko (25), have been conducted to address self-regulation, procrastination, happiness, and academic achievement, with the results unanimously calling for the necessity to heed relentlessly to students' condition, provide them with feedback, improve their selfregulation skill, and employ cheering methods in the course of academic career to add to their happiness and content and reduce their desire for procrastination.

\section{Methods}

This study was conducted under quantitive and qualitive sections. This was done by means of semi-structured interviews held with 17 psychology and educational experts. In the subsequent stage, principle issues that represented self-regulation behaviors were classified into 8 separate categories based on which the parent, teacher, and student questionnaire consisting of 127 short questions and 5 open-ended questions was ultimately prepared. Interview data were analyzed and the result was incorporated in an educational package used for training the experimental group.

In the quantitive section, the investigation followed a quasi-experimental pretest-posttest design involving a control group follow-up. Sixty students were selected by means of multi-stage cluster sampling and asked to fill out the questionnaires. Finally, 30 female and 30 male students were randomly seeded in each of the two experimental and control groups.

\subsection{Assessment Tool}

\subsubsection{Oxford Happiness Questionnaire}

This questionnaire was developed in 1989 by Argyle, Martin and Crossland. It is made up of 29 items, each item consisting of 4 phrases graded on a 0 to 3 scale. The individual ultimately obtains a score between 0 to 87 .

The range of Cronbach's alpha of questionnaire narratives under separate studies was reportedly 90\% with 347 
subjects Argyle \& Lu (26), 87\% with 101 subjects Furnham \& Brewin (27). The questionnaire was translated to Persian by Alipoor \& Noorbala (28), and Cronbach's alpha 0.93.

\subsubsection{Procrastination Assessment Scale}

The scale was developed in 1984 by Solomon \& Rothblum (29). It is made up of 27 items. Responders have options "never", "rarely", "sometimes", "frequently", and "always" to choose from.

Solomon (30) obtained a Cronbach's reliability measure of 0.79 for the whole scale. The internal consistency value of the narratives were reportedly 0.91. In an alternative study carried out with 31 student subjects, Jokar \& Rahimi (31) obtained a 0.91 and 0.84 reliability value by Cronbach's coefficient alpha and internal consistency methods respectively.

\subsubsection{Academic Achievement Standard Questionnaire}

This 60-item dual-option questionnaire was created in 2010 by Mahmood Saatchi (32) to assess student academic achievement. Scores are added to obtain a final score of 0 to 60 . The higher the score, the greater the academic achievement. Cronbach's coefficient alpha for the reliability of the questionnaire was 0.82 based on the study carried out by Saatchi to assess 40 high school students.

\section{Results}

\subsection{Postulation}

Self regulation strategy training affects procrastination, happiness, and academic achievement.

As indicated in Table 1, the Box's M test significance level (0.128) exceeding test error (0.05) verifies the assumption of homogenity of covariance matrices.

\begin{tabular}{lc}
\hline Table 1. Box's M Test for Assumption of Homogenity of Covariance Matric \\
\hline Variables & Values \\
\hline Box's M test statistic & 86.669 \\
\hline F test statistic & $1 / 2$ \\
\hline Degree of freedom & 66 \\
\hline \multicolumn{1}{c}{ 1st } & 30306.936 \\
\hline \multicolumn{1}{c}{ 2nd } & 0.128 \\
\hline Significance Level
\end{tabular}

Table 2 illustrates a meaningful difference between male and female groups in terms of their mean academic achievement, happiness, and procrastination scores. As to the effect of time variable, the mean academic achievement, happiness, and procrastination scores vary for different times (stages).
Based on the contents of Table 3, mean procrastination score for the students of the control and experimental groups shows a meaningful difference. Meantime, the significance of the effect of time/group interaction on procrastination signifies that procrastination of groups differ at varying stages (times).

Table 4 shows the significant effect of group on academic achievement. Hence, the academic achievement of the students in the two groups would be different. In Table 5 , group has a meaningful effect on happiness. Hence, on the $5 \%$ mean level, happiness for the students of the two groups is not the same.

As illustrated by Table 6, based on the results of the LSD follow-up test applied on the $5 \%$ level, there is no meaningful difference between the mean procrastination, academic achievement, and happiness scores of different groups for pretest stage. However, for posttest and follow up, the mean scores significantly differ from one group to the other.

\section{Discussion}

The result of multi-variate analysis of variance for the effect of time variable reveals the difference existing in the mean scores of the triple variables, suggesting that the extent of these variables varies by time. Similary, the separate effect of gender on these triple variables was significant. At the same time, mean scores of students in the experimental group differed from those in the control group. Hence, self-regultion strategy training has a meaningful effect on at least one of the 3 variables.

Despite of the absence of a parallel study on the effects of self-regulation training on student procrastination, academic achievement, and happiness, numerous research have dealt with these variables independantly and their findings is worthy of being considered. The study conducted by Pietrzak (22) is one good example. He demonstrated procrastination to be an underlying mechanism against the unfavorable effects of failing in self-regualtion and the result of individuals failure to meet the requirements of self-regulation program. At the same time, Hen \& Goroshit (8) came up with the conclusion that procrastination is associated with the lower levels of self-regulated learning and academic self-efficiency and is accompanied with high-level stress and anxiety. Alternatively, Schoo (24) and Karmen, Kinga \& Edit (18) revealed how procrastination is weakly related to student's academic outlook. Hence, procrastination is generally associated with negative view for academic career. Students who fulfill their assignments with enthusiasm exhibit higher academic apprehension and lesser procrastination. In a separate effort, Claessens et al (23) suggest low level of self-regulation 
Table 2. Separate Variance Analysis for Individual Variables

\begin{tabular}{|c|c|c|c|c|c|c|}
\hline Variables & Sum of Squares & df & Mean Squares & Test Statistic & Significance Level & Eta Squared \\
\hline \multicolumn{7}{|l|}{ Gender } \\
\hline A.a & 304.200 & 1 & 304.200 & 11.079 & 0.001 & 0.062 \\
\hline $\mathrm{H}$ & 2688.050 & 1 & 2668.050 & 28.368 & 0.001 & 0.144 \\
\hline $\mathrm{P}$ & 168.200 & 1 & 168.200 & 4.710 & 0.031 & 0.027 \\
\hline \multicolumn{7}{|l|}{ Time } \\
\hline A.a & 2649.811 & 2 & 1324.906 & 48.252 & 0.001 & 0.365 \\
\hline $\mathrm{H}$ & 1650.311 & 2 & 825.156 & 8.773 & 0.001 & 0.095 \\
\hline $\mathrm{P}$ & 6553.811 & 2 & 3276.906 & 91.762 & 0.001 & 0.522 \\
\hline \multicolumn{7}{|l|}{ Group } \\
\hline A.a & 1248.200 & 1 & 1248.200 & 45.459 & 0.001 & 0.213 \\
\hline $\mathrm{H}$ & 1317.606 & 1 & 1317.606 & 14.009 & 0.001 & 0.077 \\
\hline $\mathrm{P}$ & 9159.200 & 1 & 9159.200 & 256.480 & 0.001 & 0.604 \\
\hline \multicolumn{7}{|c|}{ Gender/time interaction } \\
\hline A.a & 22.033 & 2 & 11.017 & 0.401 & 0.670 & 0.005 \\
\hline $\mathrm{H}$ & 4.933 & 2 & 2.467 & 0.026 & 0.974 & 0.001 \\
\hline $\mathrm{P}$ & 35.033 & 2 & 17.517 & 0.491 & 0.613 & 0.006 \\
\hline \multicolumn{7}{|c|}{ Gender/group interaction } \\
\hline A.a & 1.800 & 1 & 1.800 & 0.066 & 0.798 & 0.001 \\
\hline $\mathrm{H}$ & 516.806 & 1 & 516.806 & 5.495 & 0.020 & 0.032 \\
\hline $\mathrm{P}$ & 1290.689 & 1 & 1290.689 & 36.143 & 0.001 & 0.177 \\
\hline \multicolumn{7}{|c|}{ Time/group interaction } \\
\hline A.a & 1290.900 & 2 & 645.450 & 23.507 & 0.001 & 0.219 \\
\hline $\mathrm{H}$ & 1027.778 & 2 & 513.889 & 5.464 & 0.005 & 0.061 \\
\hline $\mathrm{P}$ & 4221.300 & 2 & 2110.650 & 59.103 & 0.001 & 0.413 \\
\hline \multicolumn{7}{|c|}{ Gender/group/time interaction } \\
\hline A.a & 12.233 & 2 & 6.117 & 0.223 & 0.801 & 0.003 \\
\hline $\mathrm{H}$ & 5.511 & 2 & 2.756 & 0.029 & 0.971 & 0.01 \\
\hline $\mathrm{P}$ & 14.211 & 2 & 7.106 & 0.199 & 0.820 & 0.002 \\
\hline
\end{tabular}

Table 3. Results of Between-groups Analysis of Effects for Procrastination Variable

\begin{tabular}{lcccccc}
\hline Source of Variance & Sum of Squares & df & Mean Squared & F Test Statistic & Significance Level & Eta Squared \\
\hline Group & 9159.2 & 1 & 9159.2 & 91.814 & $0.001^{\mathrm{a}}$ & 0.621 \\
Gender & 168.2 & 1 & 168.2 & 1.686 & 0.199 \\
Gender/group interaction & 1290.689 & 1 & 1290.689 & 12.938 & -029 \\
Error & 5586.489 & 56 & 99.759 & -0.188 & - \\
\hline
\end{tabular}

${ }^{\text {a }}$ Significant difference at $\mathrm{P} \leq 0.05$.

\begin{tabular}{lcccccc}
\hline Table 4. Results of Between-groups Analysis of Effects for Academic Achievement Variable & & & \\
\hline Source of Variance & Sum of Squares & df & Mean Squared & F Test Statistic & Significance Level & Eta Squared \\
\hline Group & 1248.2 & 1 & 1248.2 & 18.022 & $0.001^{\mathrm{a}}$ \\
Gender & 304.2 & 1 & 304.2 & 4.392 & $0.001^{\mathrm{a}}$ \\
Gender/group interaction & 1.8 & 1 & 1.8 & 0.026 & 0.073 \\
Error & 3878.578 & 56 & 69.26 & - & - \\
\hline
\end{tabular}

${ }^{\text {a }}$ Significant difference at $\mathrm{P} \leq 0.05$. 


\begin{tabular}{lcccccc}
\hline Table 5. Results of Between-groups Analysis of Effects for Happiness Variable & & & & \\
\hline Source of Variance & Sum of Squares & df & Mean Squared & F Test Statistic & Significance Level & Eta Squared \\
\hline Group & 1317.606 & 1 & 1317.606 & 4.726 & $0.034^{\mathrm{a}}$ & 0.078 \\
Gender & 2668.050 & 1 & 2668.050 & 9.57 & $0.003^{\mathrm{a}}$ & 0.146 \\
Gender/Group Interaction & 516.806 & 1 & 516.806 & 1.854 & 0.179 & - \\
Error & 15613.2 & 56 & 278.807 & - & - & - \\
\hline
\end{tabular}

${ }^{\mathrm{a}}$ Significant difference at $\mathrm{P} \leq 0.05$.

\begin{tabular}{|c|c|c|c|c|c|}
\hline Variables & Mean & Mean Difference & $t$ & df & Significance Level \\
\hline \multicolumn{6}{|l|}{ Procrastination } \\
\hline Pretest & & 1.767 & 0.972 & 58 & 0.335 \\
\hline C & 79.1 & & & & \\
\hline $\mathrm{E}$ & 77.33 & & & & \\
\hline Posttest & & 15.667 & 9.009 & 58 & $0.001^{a}$ \\
\hline C & 77.37 & & & & \\
\hline E & 61.7 & & & & \\
\hline Follow-up & & 25.367 & 16.726 & 58 & $0.001^{a}$ \\
\hline C & 76.2 & & & & \\
\hline $\mathrm{E}$ & 50.83 & & & & \\
\hline \multicolumn{6}{|c|}{ Academic achievement } \\
\hline Pretest & & 2.033 & 1.312 & 58 & 0.195 \\
\hline C & 39.1 & & & & \\
\hline $\mathrm{E}$ & 37.07 & & & & \\
\hline Posttest & & -7.167 & -5.348 & 58 & $0.001^{\mathrm{a}}$ \\
\hline $\mathrm{C}$ & 40.93 & & & & \\
\hline $\mathrm{E}$ & 48.1 & & & & \\
\hline Follow-up & & -10.667 & -8.726 & 58 & $0.001^{\mathrm{a}}$ \\
\hline C & 41.9 & & & & \\
\hline E & 52.57 & & & & \\
\hline \multicolumn{6}{|l|}{ Happiness } \\
\hline Pretest & & 0.7 & 0.247 & 58 & 0.806 \\
\hline C & 44.73 & & & & \\
\hline E & 44.03 & & & & \\
\hline Posttest & & -5.967 & -2.263 & 58 & $0.027^{\mathrm{a}}$ \\
\hline C & 45.53 & & & & \\
\hline E & 51.50 & & & & \\
\hline Follow-up & & -10.967 & -4.186 & 58 & $0.001^{\mathrm{a}}$ \\
\hline C & 46.30 & & & & \\
\hline $\mathrm{E}$ & 57.27 & & & & \\
\hline
\end{tabular}

${ }^{a}$ Significant difference at $\mathrm{P} \leq 0.05$. 
to act as a predictive indicator of high-level procrastination. Meantime, Randy Moore (33) shows how students with higher procrastination score are more reluctant to attend class and seek assistance prior to exams. Congruent to the findings of present study on changes in students' academic achievement, Bondarenko (25) demonstrated in his investigation, the key role of presenting students with feedback and improving their level of self-regulation in improving student academic achievement.

To conclude over the findings and assumptions discussed in this study, it is worth to elaborated, once again, on the indirect effect of self-regulation training on students by empowering them to control and adjust their academic status, which inturn, is considered as one of the main factors for renforcing self-esteem. By improving the level of self-esteem and satisfaction derived from academic achievement, the individual's level of happiness experiences similar growth. In other words, the same way academic success and achievement is expected to raise the level of satisfaction and happiness in students, happy students can be expected to perform better academically. Student happiness is of crucial importance. Joy and happiness are strongly related to the sprightful spirit of the young student generation and their proper handling would promise optimization and reward. Self-regulation can be looked upon as an academic skill, which if acquired, would ultimately raise the level of happiness in students. Self-regulation training offers the essential mental tools for enhancing the academic achievement and level of happiness, and at the same time, reducing the tendency for procrastation.

\section{Footnotes}

Authors' Contribution: Study concept and design, K. N. and H. T. N. D; Analysis and interpretation of data, K. N. and H. T. N. D; Drafting of the manuscript, K. N., H. T. N. D. and H. T.; Statistical analysis, H. T.

Conflict of Interests: There was no conflict of interests. Funding/Support: There was no funding/support.

\section{References}

1. Rothblum ED, Solomon LJ, Murakami J. Affective, cognitive, and behavioral differences between high and low procrastinators. J Couns Psychol.1986;33(4):387-94. doi:10.1037/0022-0167.33.4.387.

2. Rosario P, Costa M, Nunez JC, Gonzalez-Pienda J, Solano P, Valle A. Academic procrastination: Associations with personal, school, and family variables. Span J Psychol. 2009;12(1):118-27. doi: 10.1017/s1138741600001530. [PubMed: 19476225].

3. Steel P. The nature of procrastination: A meta-analytic and theoretical review of quintessential self-regulatory failure. Psychol Bull. 2007;133(1):65-94. doi: 10.1037/0033-2909.133.1.65. [PubMed: 17201571].
4. Pintrich PR. A conceptual framework for assessing motivation and self-regulated learning in college students. Educ Psychol Rev. 2004;16(4):385-407. doi: 10.1007/s10648-004-0006-x.

5. Park SW, Sperling RA. Academic procrastinators and their selfregulation. Psychology. 2012;3(1):12.

6. Troia GA. Instruction and assessment for struggling writers: Evidencebased practices. 1st ed. New York, United States: The Guilford Press; 2010.

7. Ley K, Young DB. Instructional principles for self-regulation. Educ Technol Res Dev. 2001;49(2):93-103. doi: 10.1007/bf02504930.

8. Hen M, Goroshit M. Academic procrastination, emotional intelligence, academic self-efficacy, and GPA: A comparison between students with and without learning disabilities. J Learn Disabil. 2014;47(2):116-24. doi: 10.1177/0022219412439325. [PubMed: 22442254].

9. Magno C. Assessing academic self-regulated learning among Filipino college students: The factor structure and item fit. Int J Educ Psychol Assess. 2010;5:61-76.

10. Larson R. Is feeling "in control" related to happiness in daily life? Psychol Rep. 1989;64(3 Pt 1):775-84. doi: 10.2466/pro.1989.64.3.775. [PubMed: 2748778].

11. Wolters CA. Understanding procrastination from a self-regulated learning perspective. J Educ Psychol. 2003;95(1):179-87. doi: 10.1037/0022-0663.95.1.179.

12. Milgram NA, SroloffB, Rosenbaum M. The procrastination of everyday life. J Res Pers. 1988;22(2):197-212. doi: 10.1016/0092-6566(88)90015-3.

13. Meltzer L. Executive function in the classroom: Meta-cognitive strategies for fostering academic success and resilience. Learning differences conference. Cambridge, Massachusetts. Research Institute for Learning and Development; 2004.

14. Clarebout G, Horz H, Schnotz W, Elen J. The relation between selfregulation and the embedding of support in learning environments. Educ Technol Res Dev. 2010;58(5):573-87. doi:10.1007/s11423-009-9147-4.

15. Pekrun R. The control-value theory of achievement emotions: Assumptions, corollaries, and implications for educational research and practice. Educ Psychol Rev. 2006;18(4):315-41. doi: 10.1007/s10648006-9029-9.

16. Lyubomirsky $\mathrm{S}$. Why are some people happier than others? The role of cognitive and motivational processes in well-being. Am Psychol. 2001;56(3):239-49. [PubMed: 11315250].

17. Huebner ES, Suldo SM, Smith LC, McKnight CG. Life satisfaction in children and youth: Empirical foundations and implications for school psychologists. Psychol Sch. 2004;41(1):81-93. doi:10.1002/pits.10140.

18. Kármen D, Kinga S, Edit M, Susana F, Kinga KJ, Réka J. Associations between academic performance, academic attitudes, and procrastination in a sample of undergraduate students attending different educational forms. Procedia Soc Behav Sci. 2015;187:45-9. doi: 10.1016/j.sbspro.2015.03.009.

19. Kioslosky JL. Happiness; How are environment affects our well-being and performance. 2002. Available from: http://www.clearinghouseMwsc. edu.manuscripts/292-asp.

20. Kandemir M, Palancı M. Academic functional procrastination: Validity and reliability study. Procedia Soc Behav Sci. 2014;152:194-8. doi: 10.1016/j.sbspro.2014.09.180.

21. Zimmerman BJ. Attaining self-regulation: A social cognitive perspective. In: Boekaerts M, Pintrich PR, Zeidner M, editors. Handbook of Self-Regulation. Academic Press; 2000. p. 13-39. doi: 10.1016/B978-0-12109890-2.X5027-6.

22. Pietrzak A, Tokarz A. Procrastination as a form of misregulation in the context of affect and self-regulation. Studia Humana. 2016;5(3):70-82. doi: 10.1515/sh-2016-0016.

23. Claessens BJC, van Eerde W, Rutte CG, Roe RA. A review of the time management literature. Pers Rev J. 2007;36(2):255-76. doi: $10.1108 / 00483480710726136$.

24. Schoo A. Motivational interviewing in the prevention and management of chronic disease: Improving physical activity and exercise in line with choice theory. Int J Reality Therapy. 2008;27(2):26-9. 
25. Bondarenko I. The role of positive emotions and type of feed back in self-regulation of learning goals achievement: Experimental research. Procedia Soc Behav Sci. 2017;237:405-11. doi 10.1016/j.sbspro.2017.02.080.

26. Argyle M, Lu L. Happiness and social skills. Pers Individ Dif. 1990;11(12):1255-61. doi:10.1016/0191-8869(90)90152-h.

27. Furnham A, Brewin CR. Personality and happiness. Pers Individ Dif. 1990;11(10):1093-6. doi:10.1016/0191-8869(90)90138-h.

28. Alipoor A, Noorbala AA. [Preliminary study of the reliability and narrative of oxford happiness questionnaire used for students of Tehran universities]. J Clin Psychol.1999;5(1\&amp;2):55-65. Persian.

29. Solomon LJ, Rothblum ED. Academic procrastination: Frequency and cognitive-behavioral correlates. J Couns Psychol.1984;31(4):503-9. doi:
10.1037/0022-0167.31.4.503.

30. Solomon LJ. Procrastination assessment scale-students (PASS). In: Fischer J, Corcoran K, editors. Measure for Clinical Practice. 2. New York, NY: The Free Press; 1994. p. 446-52.

31. Jokar B, Rahimi M. [Effect of family-relation models on happiness of a group of high school students in Shiraz]. Iran J Psychiatry Clin Psychol. 2007;13(4):376-84. Persian.

32. Saatchi M.[Productivity psychology]. Tehran, Iran: Virayesh Publishing; 2010. Persian.

33. Moore R. Academic procrastination and course performance among developmental education students. Res Teach Dev Educ. 2008;24(2):56-67. 